\title{
What Drives Consumers to Accept M-ads on Their Hand-Held Devices? A Literature Review, Insights and Propositions for Emerging Markets
}

\author{
Vilasini De Silva ${ }^{1 \& 2} \& J_{u n}$ Yan $^{1}$ \\ ${ }^{1}$ School of Management, Huazhong University of Science and Technology, Wuhan, China \\ ${ }^{2}$ Department of Marketing Management, Sabaragamuwa University of Sri Lanka, Sri Lanka \\ Correspondence: Vilasini De Silva, Department of Marketing Management, Sabaragamuwa University of Sri \\ Lanka, P. O. Box 2, Belihuoya, Sri Lanka. E-mail: vilasini17@gmail.com
}

Received: April 12, 2016 Accepted: March 3, 2017 Online Published: March 10, 2017

doi:10.5539/ijms.v9n2p160 URL: http://doi.org/10.5539/ijms.v9n2p160

\begin{abstract}
Mobile phone heavily penetrates into the consumers' eventful routine and assists their shopping immensely. Marketing managers confront the query of conveyance of effectual information about products quiet often. Realizing the key dynamics of attitudes and acceptance of m-ads is crucial in designing the customized marketing message. The article attempts to give an overview on determinants of consumers' attitude and acceptance of m-ads from the existing body of knowledge. Trust and credibility is recognized as sender's characteristic that should be maintained by managers. Informativeness, entertainment, perceived ease of use and incentives are grouped into m-ads characteristics that managers should pay much attention in designing the message. And, Managers should ponder the features of target audience as well in creating the message. i.e., perceived intrusiveness, perceived usefulness, personalization and perceived control. Therefore, article is expedient in both academia and industry in emerging markets in terms of discovering elements that shape consumers' attitudes and acceptance of mobile advertising.
\end{abstract}

Keywords: mobile advertising, determinants, attitudes, acceptance

\section{Introduction}

The mobile advertising is growing along with the spread of smartphone demand and $4 \mathrm{G}$ mobile broadband technologies such as LTE (lone-term evolution) and HSPA (high-speed packet access) (Kim \& Lee, 2014). The high penetration rate of mobile phones has resulted in the increasing use of handheld devices to deliver advertisements of products and services (Tsang et al., 2004). The mobile advertising and marketing opens valuable avenues for advertisers and marketers. They grasp the chance to touch the individual consumer at personal level. This enables the marketer or advertiser to personalize their advertising message according to customer profile.

Mobile devices usually are equipped with multi media such as camera, scanner and Global Positioning System (GPS) (Strom et al., 2014). This makes mobile marketing potentially different from PC Internet and traditional marketing (Strom et al., 2014). Mobile services create additional value for consumers. They are accessible independent of time and place (Balasubramanian et al., 2002; Chen \& Nath, 2004), being customized based on time, location and personal profile (Figge, 2004), self-ascribed roll categories (professional (on duty), and private (off duty) and stance categories (busy, time on hand, waiting) (Dholakia \& Dholakia, 2004).

The mobile advertising industry is growing rapidly and fragmenting into many branches. This paper attempts to gather and analyze literature about factors underlying mobile advertising. The paper is organized according to the numerous factors which were experimented and discussed in many research studies.

\section{Mobile Advertising}

\subsection{Why Mobile Advertising?}

Mobile devices have emerged as a new channel for marketing communication, with its unique features like ubiquity, interactivity and persuasive nature. Mobile marketing has exploded worldwide with mobile device/phone penetration reaching six billion (Banerjee \& Dholakia, 2012). From global perspective, Gartner 
(2014) reports, worldwide mobile advertising revenue is to reach $\$ 24.5$ billion in 2016 . Accelerating numbers in revenue implies that mobile advertising is over-taking traditional media with its unique characteristics. Some motivations for companies to migrate towards mobile platforms are the possibilities the technology offers for establishing a relatively more personal and interactive communication with their consumers at lesser cost and create strategies that are specific to the location of a consumer within a context of consumption (Meyll et al., 2014). This customization is better matched with customers' needs and improves client relationship than much advertising in traditional media. Given these possibilities and benefits marketers as well as consumers have been addicted to use mobile beyond their basic communication needs and wants.

\subsection{Definition and Types of $M$-ads}

Mobile advertising refers to advertisements sent to and received by mobile devices, i.e. cellular phones, Personal Digital Assistants (PDA), and other handheld devices which people carry with them (Salo \& Tahtinen, 2005). The Mobile Marketing Association defines mobile marketing is a set of practices that enables organizations to communicate and engage with their audience in an interactive and relevant manner through and with any mobile device or network (Mobile Marketing Association, 2015). There are many types of mobile advertising for different communication methods and advertising purposes. Various types $\mathrm{M}$-ad brings differentiated benefits to the marketer and consumers. Currently, the most common forms of mobile advertising include text messaging (i.e., SMS) and multimedia messaging (i.e., Multimedia Messaging Service/MMS). SMS text messages are in plain text format, which is readable by nearly all cell phones. Therefore, SMS is currently the most widely used form of advertising. The Table1 summarizes the types of M-ads identified by various authors. Further, Figure 1 describes how M-ads could be classified according to its nature.

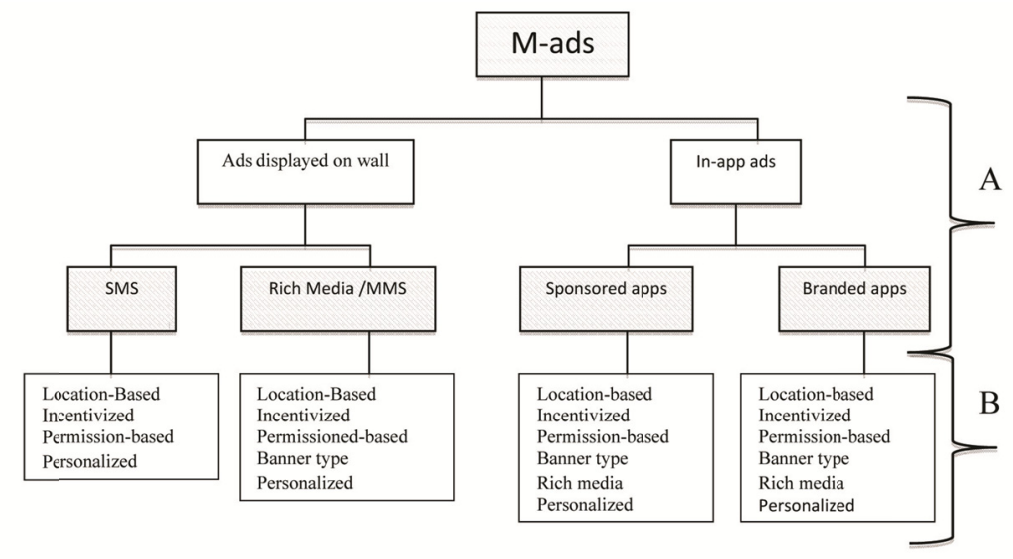

A- M-ads classified according to issue channel

B- M-ads classified according to issue strateg!

Figure 1. Classification of M-ads

Table 1. Types of M-ads studied

\begin{tabular}{ll}
\hline Type of M-ad & Author/s \\
\hline SMS & Beneke et al. (2010), Carroll et al. (2007), Drossos et al. (2007), Haq (2012), Liu et al. (2012), Maneesoonthorn \& \\
& Fortin (2006), Nantel \& Sekhavat (2008), Tsang et al. (2004), Varnali et al. (2012), Zhang \& Mao (2008), Gavilan et \\
& al. (2014) \\
& Gavilan et al. (2014) \\
MMS & Bhave et al. (2013) \\
In-app ads & Chen, P. T. \& Hsieh, H. P. (2012), Kim, Y. J. \& Han, J. Y (2014), Xu et al. (2008), Xu, D. J. (2006-2007) \\
Personalized M-ads & Choi et al. (2008), Chowdhury et al. (2006), Damnjanovic \& Milicevic (2010), Gao et al. (2009), Gao et al. (2010), \\
M-ads in general & Hanley et al. (2006), Jun \& Lee (2007), Koury \& Yang (2010), Kim K. J. (2014), Kolsaker \& Drakatos (2009), Kim \\
& \& Heo (2010), Khan \& Allil (2010), Li \& Stoller (2007), Merisavo et al. (2007), Ma et al. (2009), Nasco \& Bruner \\
& (.....), Okazaki et al. (2007), Parreno et al. (2013), Peng (2006), Park \& Salvendy (2012), Rau et al. (2014), Sung \& \\
& Kwangsu (2012), Truong \& Simons (2010), Unal \& Keser (2011), Vatanparast \& Butt (2010), Xie et al. (2013), Yang \\
& et al. (2013), Yang (2007), Akpojivi \& Dye (2015), Yang et al. (2010), Yu (2013), Watson et al. (2013), Yusta et al. \\
& (2015), Chen et al. (2014), Rohm et al. (2012), Wong et al. (2015), Im \& Ha (2013), Goh et al. (2015), Bakar \& Bidin \\
& (2014), Persaud \& Azhar (2012) \\
& Leppaniemi \& Karjaluoto (2008) \\
Interactive Ads & Unni \& Harmon (2009), Persaud \& Azhar (2012) \\
Location-based &
\end{tabular}




\subsection{Does One Size Fit All?}

Theories related technology acceptance, consumer behavior, communication and so forth have been used to develop various conceptual models for studies in mobile advertising. Review evidences most likely used theories are Uses and Gratification theory (Choi et al., 2008; Chowdhury et al., 2006; Jun \& Lee, 2007; Kim \& Han, 2014; Liu et al., 2012; Ma et al., 2009; and Parreno et al., 2013), Theory of Reasoned Action (Kim \& Han, 2014; Khan \& Allil, 2010; Tsang et al., 2004; Unal \& Keser, 2011; Xu, 2006-2007; and Yang et al., 2013) and Technology Acceptance model (Kim \& Han, 2014; Koury \& Yang, 2010; Khan \& Allil, 2010; Yang et al., 2013; Yang, 2007; Zhang \& Mao, 2008; Yusta et al., 2014 and Bakar \& Bidin, 2014). Except there are other theories like Social Norm Theory (Koury \& Yang, 2010), Theory of Planned Behavior (Yang et al., 2013; Yang et al., 2010), Flow Theory (Kim \& Han, 2014) and Web Advertising Model (Kim \& Han, 2014) which have been used.

\section{Determinants of Attitude towards M-ads}

Factors pertaining to theories mentioned above have been given the priority in reviewing in the article. There are various other studies that examine novel concepts in relation to the mobile advertising as well. Such studies bring new insights to the mobile marketing literature and provide implications in innovative thinking for practitioners. However, those novel concepts and determinants need further attention and investigation in mobile advertising research. Factors observed by various authors have been summarized in Table 2. Further, classification of factors/determinants considered in the review is shown in Figure 2.

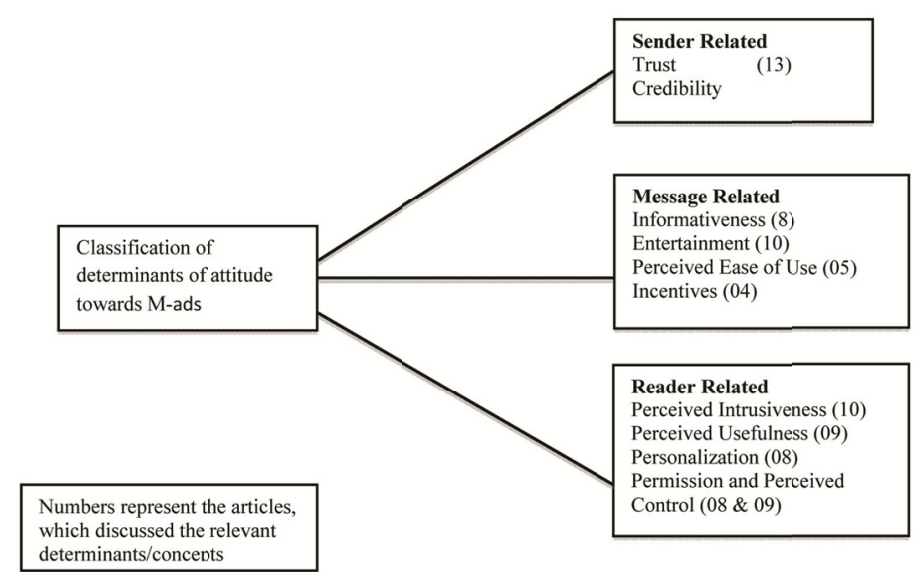

Figure 2. Classification framework for determinants of attitude towards M-ads (considered in the review)

Table 2. Predictors/variables considered in each research

\begin{tabular}{lll}
\hline Category & Predictor & Author/s \\
\hline Device & Screen size of the phone & Bhave et al. (2013), Li \& Stoller (2007), Xie et al. (2013) Watson et al. (2013) \\
Related & Type of mobile device & Chen, P. T. \& Hsieh, H. P. (2012) \\
& Specialized Mobile Technology & Kim K. J. (2014) \\
& Technology based evaluations & Yang et al. (2013) \\
\hline Ad Related & Content & Beneke et al. (2010), Carroll et al. (2007), Nasco \& Bruner (.....), Varnali et al. (2012) \\
& Text/SMS & Bhave et al. (2013), Nasco \& Bruner (.....), Sung \& Kwangsu (2012), Gavilan et al. (2014) \\
& Ad relevancy & Bhave et al. (2013) \\
& Informativeness & Choi et al. (2008), Chowdhury et al. (2006), Kim, Y. J. \& Han, J. Y (2014), Tsang et al. (2004), \\
& Unal \& Keser (2011), Xu, D. J. (2006-2007), Wong et al. (2015), Goh et al. (2015) \\
& Entertainment & Choi et al. (2008), Chowdhury et al. (2006), Kim, Y. J. \& Han, J. Y (2014), Ma et al. (2009), \\
& Parreno et al. (2013), Tsang et al. (2004), Unal \& Keser (2011), Xu et al. (2008), Xu, D. J. \\
& (2006-2007), Yang (2007) \\
& Kerceived ease of Use & Bidin (2014) \\
& Jung \& (2010), Zhang \& Mao (2008), Yusta et al. (2015), Im \& Ha (2013), Bakar \& \\
& Multi Media Service & Kim, Y. J. \& Han, J. Y. (2014), Liu et al. (2012), Unni \& Harmon (2009), Yusta et al. (2015), \\
& Advertising Value & Persaud \& Azhar (2012) \\
& Liu et al., (2012) \\
& Nasco \& Bruner (.....), Yang (2007) \\
& Audio and Video messages & Nantel \& Sekhavat (2008) \\
Text Language & Im \& Ha (2013) \\
Information disclosure &
\end{tabular}




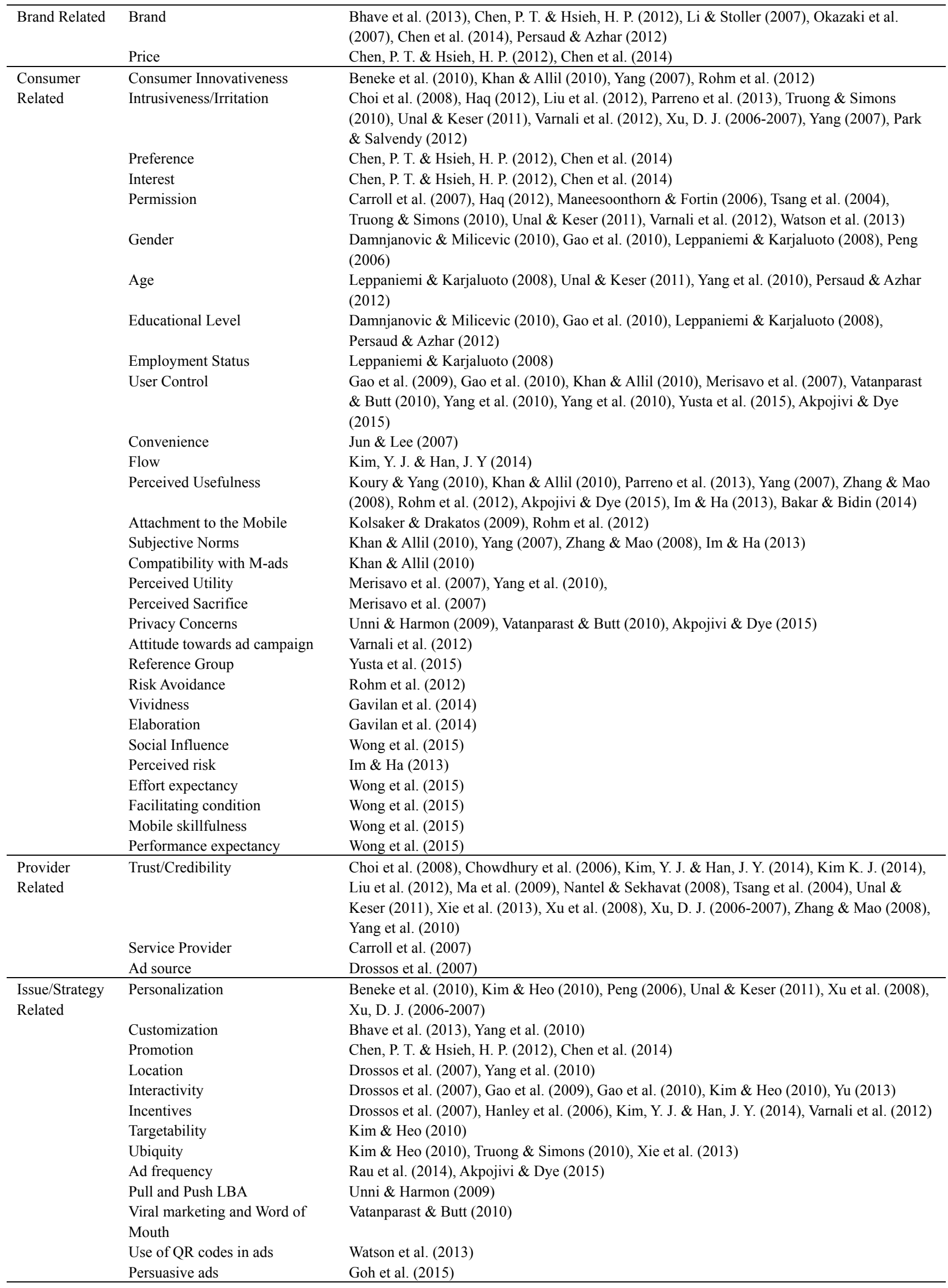




\subsection{Sender Related}

\subsubsection{Trust}

Trust is an important and essential component in maintaining relationships. To initiate a relationship favorably trust should be implanted first. Trust is defined as one's confidence in another party's reliability and integrity (Morgan \& Hunt, 1994). In marketing, trust is broadly defined as "a willingness to rely on an exchange partner in whom one has confidence" (Moorman et al., 1993). Trust has always been an important issue in studying advertising, either for an ethical or for a practical concern (Zhang \& Mao, 2008).

Trust in online environment is characterized by greater complexity (e.g., trust in the web site vs. trust in technology), need for structural assurance of security and privacy, and the lack of tangible brand cues (Pentina et al, 2013). Authors state that the impersonality, anonymity and automation of electronic transactions and communications make it difficult for consumers to evaluate the trustworthiness of online vendors and other consumers. Literature in m-ads gives proof that trust has been applied directly in m-ads research studies to determine the relationship with the m-ads adoption intention.

It has been demonstrated that trust is a strong determinant of positive attitudes of Chinese consumers towards SMS ads (Short Messaging Service) (Zhang \& Mao, 2008) and towards M-ads in general (Xie et al., 2013) too. Among Finland consumers, trust was found to be positively influencing on attitudes towards overall M-ads (Merisavo et al., 2010). Yang and colleagues (2010) reported that, mobile marketers should earn consumers' trust in both USA and Chinese context, as it is an universal facilitating factor predicting young consumers' acceptance of M-ads. Unni \& Harmon (2009) found that consumer's trust to the message sender positively related (in varying degrees) to their signing up behavior of location-based M-ads or attitudes of location-based mobile advertising.

\subsubsection{Credibility}

Authors evidence the construct credibility has been used interchangeably with the construct trust. Conventional wisdom says that credibility is necessary for effective advertisement (Kim \& Han, 2014). Credibility, which refers to a confident belief in the reliability and integrity of advertisers, plays an important role in determining ad effectiveness and building long-term relationships between advertisers and consumers (Yang et al., 2013). The theories of credibility have been and will be of significance to researchers and practitioners within the field of promotion and advertising (Aziz et al., 2013). In examining factors influencing attitude of consumers towards m-ads the credibility shows positive relationship in many research studies. Kim \& Han (2014) and Yang et al. (2013) stated credibility plays a positive and vital role in predicting advertising value of personalized M-ads for South Korean consumers. Similarly, Liu et al. (2012) report credibility predicts the advertising value of SMS ads in both Austrian and Japanese context. Bolstering the above findings, it has been disclosed Chinese consumers welcome more credible ads (Xie et al., 2013), search for credibility of personalized mobile advertising applications (Xu et al., 2008) and seek for credibility in personalized M-ads Xu (2006-2007) as well. Further, Choi and associates (2008) disclosed in their comparative study between US and South Korea accounts credibility is equally considered by both consumers in their purchase intention towards M-ads. Additionally, Ma and others (2009) reported US consumers pursue credibility in developing positive attitude towards M-ads.

Similarly, few studies in emerging markets produce results in parallel to above findings. Unal and colleagues (2011) demonstrated Turkish consumers are more likely to search for credibility in M-ads generally in forming positive attitude. Bolstering above results, Tsang and others (2004) concluded credibility is positively correlated to the overall attitude towards SMS ads in Taiwan. Chowdhury and associates (2006 in Bangladesh) discovered positive and significant relationships between credibility and attitude towards M-ads.

Although a majority of researches asserted the positive effect of credibility, minority in different countries got inconsistent evidence. Bhave et al. (2013) revealed that Indian consumers do not consider brands advertised in in-app advertisements as credible. Thus, marketers and advertisers have many implications from these studies to be considered in formulating their advertising strategy.

\subsection{M-ad Related}

\subsubsection{Informativeness}

The main purpose of advertising is to provide information for its target consumers. When news or messages hit customer needs, customers enjoy understanding details (Kim \& Han 2014). Deception in advertising may occur mainly because of false information. Hence, providing more accurate information is critical in attracting and retaining consumers. Cues of product quality, components/content, price/value, and availability significantly increase the perceived informativeness of the advertisements (Soley \& Reid, 1983). But increasing the amount of 
information in advertising content does not necessarily make advertising more informative. Thus, quality of information in the advertisements is much more important.

A lot of authors proved informativeness is a strong predictor of advertising value of M-ads. Choi and associates (2008) observed informativeness is more important for US consumers than Korean consumers in relation to determining advertising value and the purchase intention. Likewise, Kim \& Han (2014) reported informativeness is a strong predictor of advertising value of personalized M-ads in South Korea. Informativeness has been revealed as a strong determinant in deciding ad value in Austria and Japan too (Liu et al., 2012). It has been revealed that informativeness as a significant predictor of Turkish consumers' (Unal et al., 2011) and Chinese consumers' (Xie et al., 2013) attitude towards M-ads. Consistently, informativeness was found to be a positively correlated factor with overall attitude towards SMS ads in Taiwan (Tsang et al., 2004). Interestingly, Goh and associates (2015) reports informative ad content has different effects on the depth and breadth of information search related to M-ad.

However, some authors reported controversial findings in certain contexts. Chowdhury and others (2006) stated there is a negative relationship between informativeness and consumers' attitude toward M-ads in Bangladesh. They explained that, consumers who receive the m-ads with much information may not like to read the whole message due to small screen size, cost of traffic, technology problems, etc. Marketers and advertisers too have many implications from mobile advertising literature regarding providing information in M-ads to consumers.

\subsubsection{Entertainment}

We can say that food is strongly related to our physical sustainability, yet at the same time, we can point out that entertainment is related to our mental and spiritual sustainability (Nakatsu, 2010). Entertainment aspect could be the most attractive feature of a message. Thus, entertainment is asserted to be another important construct used in evaluating the attitudes of consumers towards m-ads. Entertainment in communication can increase customer loyalty and add value for the customer (Haq, 2012). Haq (2012) states most people have a natural playfulness thus, providing games and prizes via text messaging yields high participation.

Most of the studies revealed that entertainment factor has positive relationship with attitudes toward mobile advertising and adoption intention of m-ads. Choi et al. (2008) stated that both USA consumers and Korean consumers consider entertainment as the major factor in accepting M-ads. Kim \& Han (2014) reported entertainment as a positively correlated factor with personalized M-ads among South Korean consumers. Besides, $\mathrm{Xu}$ and others (2008) demonstrated the similar result in accepting personalized M-ads in Chinese context. It is disclosed that entertainment is more likely to influence attitude towards M-ads positively in Turkish context as well (Unal \& Keser, 2011). Taiwan consumers too consider entertainment as positively correlated with the attitude towards SMS ads (Tsang et al., 2004). Further, Parreno and associates (2013) confirmed entertainment significantly influence acceptance of M-ads in Spain. Interestingly, Yang (2007) concluded that attitude towards m-commerce predicts consumers' intention to use M-ads as enjoyable. Similarly, it has been revealed that entertainment is positively correlated to attitude towards SMS-ads in India (Haq, 2012) and M-ads in US (Ma et. al., 2009). And Xie and associates (2007) too explored that entertainment does affect positive attitudes about personalized mobile advertising applications in China.

In contrast to the above findings, an early Chinese study done by Xu (2006-2007) found entertainment is lesser important in personalized M-ads. Studies done by Chowdhury and others (2006) in Bangladesh and Kolsaker \& Drakotos (2009) in United Kingdom disclosed that consumers perceive m-ads are not entertaining/enjoyable and it negatively influences their attitudes. Marketing practitioners have the opening to enhance the value of their advertisements through this aspect as well.

\subsubsection{Perceived Ease of Use}

Perceived usefulness and perceived ease of use are the two fundamental components of assessing and predicting ones' new technology adoption and usage behavior (Kucukusta et al., 2014). These two key determinants are proposed and tested in the original and revised Technology Adoption Model in various scenarios and in various consumer groups as well. Furthermore, Im \& Ha (2014) states when one perceives a technology to be easy to use, he/she also perceives the technology to be useful, which in turn enhances intention to use the technology. Davis (1989) defined ease of use as "degree to which a person believes that using a particular system would be free of effort." When all other things are equal, an application that is perceived to be easier to use than another is more likely to be accepted by users (Lee et al., 2008). Academic and industry marketing research also indicate that ease and convenience of use is a prerequisite of consumers' acceptance of mobile commerce (Adhami, 2012).

The technical and interactive characteristics of mobile media, in comparison with other media such as television 
or magazines, mean that consumers' experience (UX-User Experience) of mobile advertising differ from those of advertising in other media (Yusta et al., 2014). Specifically, before respond to the advertisement consumer should gain access to the M-ad. Precisely, consumers need to check and gain access to a M-ad by first maneuvering through menus, then read and understand the message, and finally make a quick evaluation of whether it is worthy (in terms of time or effort) to take the action, e.g., providing their comments on products (Zhang \& Mao, 2008). Therefore ease of use of the particular technology (medium) should be guaranteed to gain attention of the consumer towards the M-ad.

Therefore interestingly, many studies conclude perceived ease of use as a strong dimension of attitude towards M-ads. Parreno and associates (2013) too disclosed ease of use is an influential factor in forming or shaping attitude towards M-ads among Spanish consumers. Zhang \& Mao (2008), examined ease of use as a predictor of Chinese consumers' attitude towards SMS ads. A recent study in Spain about M-ads by Yusta and others (2015) concluded ease of use predicts positive attitude towards M-ads. Im \& Ha (2013) in their study about mobile coupons stated perceived ease of use is positively related to attitude towards mobile coupons. Bakar \& Bidin (2014) too found perceived ease of use is related to actual use of ad content. In contrast Koury \& Yang (2010) stated perceived ease of use doesn't predict attitude towards M-ads.

\subsubsection{Incentives}

Incentive is also an important factor in determining the attitudes towards M-ads. Customers are interested in tangible benefits and give more attention to an advertising message for financial advantage (Kim \& Han, 2014). This may increase the attractiveness of the advertisement. Kim \& Han (2014) revealed that incentive has a positive relationship with the advertising value which is a predictor of adoption intention. Providing incentives can increase the intention to receive SMS-based mobile advertisements was found in the studies done by Tsang, and others (2004) (A Taiwan study about SMS ads) and Drossos and others (2008) (A Greece study about SMS ads). Further, Unal and others (2011) (A Turkish study about M-ads) reported youth are more positive towards advertisements with incentives and tend to benefit from mobile advertising more than adults. A US based study about M-ads by Hanley and others (2006) stated college students would consider accepting ads on their cell phone if specific cell phone ad delivery conditions are met (e.g., if free cell phone products and services or monetary incentives are offered). Another US based study about M-ads by Jun \& Lee (2007) concluded that consumer attitudes are directly linked to behavioral intentions for m-ads such as getting free coupons, calling back, sending texts, visiting specific shops. Varnali and others (2012) too discovered that incentives and attitudes about SMS-ads are positively correlated in Turkish context. Having evidenced that, it could be said that incentive is also an important factor in determining the attitudes toward mobile advertising. These are interesting findings for marketers and advertisers to be applied in mobile advertisements preparation.

\subsection{Reader Related}

\subsubsection{Perceived Intrusiveness/Irritation}

Advertisements could produce positive results and negative results as well. If an audience detects advertisements as intrusive, it would result in negative consequences. Intrusiveness is a perception or psychological consequence that occurs when an audience's cognitive processes are interrupted ( $\mathrm{Li}$ et al., 2002). If advertisements are intrusive to some extend, then an important question is: What is it that causes advertisements to be perceived as intrusive (Ying et al., 2009). Ha (1996), defined intrusiveness as the degree to which advertisements in a media vehicle interrupt the flow of an editorial unit. Reactance theory posits that individuals like to preserve their freedom to evaluate an object. When this freedom is threatened, they will resist persuasion (Brehm \& Brehm, 1981). Further, the smaller size of the screen was raised as an issue, which is more sensitive to intrusive advertising, formats on mobile phones (Truong \& Simmons, 2010). And push digital advertisements on the internet and mobile platforms were largely viewed as intrusive. Intrusiveness describes the mechanism by which ads evoke negative emotional reactions, such as irritation or annoyance, but not the negative emotional reactions themselves (Li et al., 2002).

A comparative study between US and Korea by Choi and associates (2008) revealed US consumers have high concerns about irritation than Korean consumers in accepting M-ads. Unal \& Keser (2011) reported youth see M-ads are more irritating than adults in Turkish market. Another study in Turkey by Vernali (2012) about SMS advertising concluded perceived intrusiveness exerts a negative impact on response behavior. Kim \& Han (2014) demonstrated an interesting finding in the Korean study about irritation in relation to personalized smartphone advertisements. They reported irritation has a negative impact on flow experience of consumers towards smartphones and irritation doesn't influence customer perception about advertising values. Irritation was found to be more influential (negatively) in Japanese culture than Austrian culture in accepting SMS ads (Liu et al., 
2012). Tsang and his associates conducted a study about SMS ads in Taiwan in 2004, and concluded that irritation is negatively correlated to overall attitude towards SMS advertising. Parreno and his associates (2013) mentioned irritation significantly and negatively influence attitude of Spanish consumers towards M-ads generally. Similarly, Truong \& Simmons (2010) too reported UK consumers are more sensitive to intrusive nature of M-ads on their mobile phones. An Indian study done by Haq (2012) concluded irritation is negatively correlated with attitude towards SMS ads.

There are contrary findings about irritation towards M-ads as well. M-advertising is intensively used in Chinese context. $\mathrm{Xu}$ and associates (2008) and $\mathrm{Xu}$ (2006-2007) stated irritation is not an important attribute in determining behavioral attitude towards personalized M-advertising applications and personalized $\mathrm{M}$-ads as well in Chinese context. Corresponding to the above, irritation was found to be positive and insignificant for Bangladesh consumers in developing attitude towards M-ads (Chowdhury et al., 2006). Interestingly, Yang (2007) too reported Taiwan consumers' attitude towards using M-commerce predicts consumers' intention to use M-ads non-intrusive. Park \& Salvendy (2012) mentioned irritation is a primary attitude towards M-ads in their USA study. Possibly irritation could be considered as a factor which enhance the memory of the consumer regarding the m-ad. Once the advertisements are irritating or disturbing too much, consumers tend to remember the advertisement more.

\subsubsection{Perceived Usefulness}

The other determinant in Technology Acceptance Model is perceived usefulness. Davis (1989) defines perceived usefulness (PU) as the degree to which a person believes that using a particular system would enhance his or her job performance. From the original definition and other related constructs, it is clear that perceived usefulness refers to the value as perceived by users of an Information System on improving their job performances (Yeh \& Teng, 2012). Perceived usefulness is a strong predictor in determining adopting m-ads. Koury \& Yang (2010) reported perceived usefulness predicts attitudes towards M-ads positively. Zhang \& Mao (2008) found it as a strong predictor of behavioral intention of Chinese consumers in SMS advertising. Enriching the literature, Parreno and others (2013) in their Spanish study discovered perceived usefulness significantly influence attitude toward M-ads positively.

Merisavo and others (2009) added to the literature that there is a strong path between Finland consumers' perceived utility and m-ads and willingness to accept M-ads from his findings. Yang (2007) reported attitudes toward using m-commerce positively shape Taiwan consumers' attitude towards usefulness of M-ad. Corresponding to the above findings, Khan \& Allil (2010) reported perceived usefulness is an important determinant in India in adoption of M-ads compared to Syria. Furthermore, Yang and others (2010) found perceived utility or usefulness is a consistently significant determinant of consumer acceptance of m-ads in US, China as well as in Finland. Bakar \& Bidin (2014) enriched M-ad literature in a different perspective. They conducted a study in the area of movie m-ads in Malaysia and concluded perceived usefulness is directly related to actual use of Ad content. In a US study related to mobile coupon, it has been revealed perceived usefulness is positively related to attitude towards mobile coupons (Im \& Ha, 2013). A comparative study done among US, China and Western Europe by Rohm and associates (2012) reveals US respondents perceive greater usefulness and attachment than China and Western Europe.

However, Akpojivi \& Dye (2015) reported divergent results about perceived usefulness form their South African study. They found no relationship between perceived usefulness and desire to control M-ads. Most of the studies reveal consumers expect $\mathrm{M}$-ads to be useful in order to form positive attitude toward M-ads.

\subsubsection{Personalization}

Personalization is another key predictor of M-ads adoption. Compared to its significance in other types of advertising, personalization is a more important factor in mobile advertising (Xu et al., 2008). Personalization distinguishes the mobile environment from traditional media. The advent of the smartphone enables customer profiling and tracking customer activities and location (Kim \& Han 2014). This helps to identify the individual tastes of consumers and deliver a more personalized ad. Customers are receptive to advertising that is personalized and relevant to their lifestyle (DeZoysa, 2002). Xu and others (2008) stated the components of personalization include individual demographic information, user preference, merchant's information and environment contexts in their Chinese study.

Kim \& Han (2014) reported personalization has been proven to be a strong predictor of informativeness and credibility which are key determinants of m-ads adoption intention in the Korean context. More precisely, Xu and others (2008) found the most important factor influencing personalization of Chinese consumers is the context factor, followed by user preference and content respectively. Further, Unal and associates (2011) too 
reported personalization is an important attribute among Turkish consumers in accepting M-ads in general. Peng (2006) in his study about M-ads in China also showed personalization has a positive effect on attitude toward mobile advertising as a mean of delivering trust and offering credible and trustworthy information. Xu (2006-2007) too confirmed the same findings as above in the Chinese context. South African study on SMS ads by Beneke and others (2010) reported personalization has a positive relationship with attitude towards SMS ads. Matching with above finding Korean consumers too rank personalization as a key attribute in using M-ads (Kim et al., 2010). Yang and associates (2010) reported Chinese consumers are more likely to accept customized M-ads than US consumers. And, Bhave (2013) too mention Indian customers are willing to accept more customized in-app ads.

Surprisingly, Ma and others (2009) concluded US consumers do not believe ads received via mobile phones are customized according to their preferences. Personalization/Customization has been explored to be an important attribute in influencing consumers' attitude towards M-ads.

\subsubsection{Permission of the Consumer and Perceived Control}

Since the handheld devices are personal and private in nature consumers show strong willingness to control advertisements that come to their mobile phones. The studies revealed that there is a strong correlation between permission of the consumer/perceived control with the positive attitudes of m-ads. Unal and associates (2011 in Turky) stated consumers highly care permission when accepting M-ads. Similarly, Taiwan consumers too have high concerns about permission in accepting SMS ads (Tsang et al., 2004). Carroll and others (2007) and Maneesoonthorn \& Fortin (2006) reported permission-based SMS ads yields high positive results in New Zealand context as well. The above results are valid for M-ads in North American, European and Asia context too (Vatanparast \& Butt, 2010). Furthermore, Haq (2012) showed once permission is obtained results are positive for M-ads in India. This particular scenario is comparable among Chinese consumers too (Gao and others, 2009).

Besides, control of M-ads has been emerged as a predictor in intention to adoption of M-ads in India but not in Syria (Khan \& Allil, 2010). Furthermore, Beneke and others (2010) examined lack of control of m-ads leads to negative attitudes towards SMS-ads in South Africa. Watson and her associates (2013) reported being able to control frequency of SMS and other text messaging and stop text easily is also a key factor in determining acceptance among UK consumers.

Contradictory results too have been revealed in the review. Varnali and others (2012) stated permission is insignificant among Turkey consumers in accepting SMS ads. Equivalent to the above Yang and others (2010) too reveal perceived control is not significant in US and China.

\section{Conclusion}

As a result of the rapid development of modern technology, Internet and mobile networks have become interwoven in the everyday lives of people (Chen et al., 2014). Handheld devices have started to offer different mobile services to customers and marketers too. With the advent of smartphone simple communication via mobile phones has been augmented in to various other areas like social networking, browsing, blogging, and so forth. Moreover, customers are exposed to large amount of data with this paradigm shift. This scenario has been creating countless avenues for the marketing industry while giving more preferences to customer. Contemporary customer who is well aware about happenings around the world expects the best from his/her product/service provider.

The literature review provides use some useful directions in understanding and making use of M-ads. Lots of studies have been taken placed in developed economies and rapidly developing economies. Very fewer studies were taken place in emerging markets. Therefore, studying how emerging economies react to $\mathrm{M}$-ads is much more important. The review highlights that most of the studies were mainly limited to Technology Acceptance Model and Theory of Planned Behavior. Most of the cultural aspects, communication aspects, and consumer psychological aspects have been overlooked. Researchers have immense array of ways, methods, and theories to test in the emerging economies and come up with even newer findings. Therefore, Academia, other research fellows and practitioners in such markets need to initiate, divert and expand their work into in depth investigating behavioral aspects of M-ads. The situation is such, importantly; marketers too need ways to understand insights of mobile marketing and consumers' behavioral aspects related to M-ads. As consumers heavily using mobile devices and rely on such for their day to day activities, it is important for marketers to acquire a deep understanding of the concepts and phenomena connected to mobile advertising. More literature is needed as mobile technology industry is rapidly developing and more work is needed to guide firm's strategies and tactics as consumer psychology is changing with complex needs and wants. 


\section{Managerial Implications for Emerging Markets}

Mobile marketing has exploded worldwide with mobile device/phone penetration reaching six billion (Banerjee $\&$ Dholakia, 2012). From global perspective, Gartner (2014) reports, worldwide mobile advertising revenue is to reach \$ 24.5 billion in 2016. According to the 2012 Mobile Advertising Survey by Hipcricket (www.hipcricket.com), 46 per cent of smartphone owners have viewed a mobile ad, and 64 per cent of those who have viewed an ad have made a purchase as a result of mobile advertising. Among those who have viewed a mobile ad, the type of ad viewed was as Mobile banner: 70 per cent, SMS/text message: 44 per cent, AD within a mobile game or app: 42 per cent, Mobile video: 38 per cent, and Mobile email: 31 per cent (www.hipcricket .com). These sky touching numbers provide ample of opportunities for practitioners and researchers. However, M-ads are not new to developed economies like US, UK and other European countries and rapidly developing countries like China, South Korea and India. The M-ad literature too contains lots of studies from these economies. Mobile advertising is becoming popular in emerging markets too. However, reports from new emerging market are insufficient. Thus, these accelerating numbers are providing quite useful insights for practitioners and researchers in emerging markets. Furthermore, this scenario implies that this is the high time for emerging markets to enter into M-ads industry.

The unique differentiator of the mobile marketing platform is marketers' ability to reach consumers untethered in the context of their daily routines and lifestyles, and not just in the context of their offices or living rooms (Rohm et al., 2012). It opens up an entirely new suite of applications allowing marketers to reach consumers with contextually relevant advertising and promotions. Managers should start building strategy from overall consumers and seek to tap into the individual characteristics; marketers need to think about where their customers live, and what cultural and social forces may influence their behavior in the mobile space. To address this scenario, marketers try to use more personalized form of M-ads to reach customers in the world of BIG DATA. With increasing bandwidth and the development of smartphones, mobile advertising applications have also become personalized and diversified. Branded mobile apps (apps dedicated to the brand), location-based services, in-app ads, and so forth are emerging strategies of marketers to reach customers more personal level.

Pervasive nature of the mobile technology and the advent of M-ads has opened up the possibility for marketers to reach individual consumer in the correct place, at the perfect time, and in interactive way (Peters et al., 2007 as cited in Yu, 2013, p. 6). Hence, companies should try to integrate M-ads as a promotional tool in their promotional mix. Yu (2013) had indicated that consumers have different psychology in responding to ads while at home and while travelling. This implication is very much useful in providing location -based services to consumers in more customized way. Consumers prefer to provide their location- based information especially when they are on the go. The location-based ads facilitate and make consumers comfortable on their journeys by providing information to find food and lodging, tourist destinations, transportation, and other useful travelling tips. Sometimes, using m-ads to search for information is a time-saving factor for eventful consumers. Further, unsurprisingly as modern consumers expect more transparency and ways of interactivity, marketers can't rely on traditional advertising methods or communication tools anymore. To address this issue, marketers can use the inherent advantage of mobile advertising in driving consumers' response by clicks or conversation events (Rosenkrans \& Myers, 2012, pp. 5-21). Conversation type or any other action type mobile ads keep consumers alive and active with the ad. When the ad encompasses activities consumers are motivated to act with the ad which results a positive or a negative response.

The customization can increase the response rate to m-ads than that of traditional media. Mokbel \& Levandoski (2009) (cited in Rosenkrans \& Myers, 2012, pp. 5-21) asserted that advertising contents should be personalized or matched to users' preferences and profile. M-ads could be customized easily as mobile media is highly interactive with the customer. In the context of permission marketing, it has been found that if a commercial message is personalized, it may be perceived as valuable information as opposed to "interrupt marketing" (Bhave et al., 2013). In the subject of SMS (Short Messaging Service) advertising/marketing, it helps to enrich the effectiveness of traditional advertising campaigns when they are coupled. When compared to SMS, MMS (Multi Media Messaging Service) can increase the effective rate of M-ads. MMS can accelerate the brand recall in consumers' memory with different effects embedded in the message itself and it would influence the purchase intention as well. Nevertheless, advertisers and marketers should handle SMS/MMS properly in promoting their thoughts to their customers as unnecessary SMS/MMS overloaded in consumers' mobile device can interrupt the customers' intention to use the M-ad. 


\section{Future Research in M-ads in Emerging Markets}

\subsection{In-Depth Research in M-ad Characteristics}

The reviews in the article highlight various areas to investigate further. Many studies were limited to theories like Technology Acceptance Model (TAM), Uses and Gratification theory (U \& G) and Theory of Reasoned Action (TRA). Technological aspects of mobile advertising were given relatively a high attention. Since there is a need for superior $\mathrm{M}$-ad designs to meet fragmented needs and wants of a contemporary customer, new research work is needed in this aspect, e.g., Ad language, Ad timing, Ad frequency, Ad pictures (static/motion), Ad placement, In-app ads, Location-based ads and so forth. Gaining better insights of these characteristics would support to design better-personalized M-ads to the customer with less irritation.

\subsection{In-Depth Research in Product/Service Attributes or Brands}

Another aspect which was ignored but which is imperative is brands or product features. This perspective would be in great need to be explored for marketers to develop customized strategies and tactics in consumers' mobile device. More work need to be done in searching most suitable attributes of brands to advertise via M-ads. Furthermore, what types of products/services/brands are mostly suited for M-ads should be determined. Thus, it would be very fruitful to fragment the research work into many more areas that will enrich the literature about m-advertising.

\subsection{In-Depth Research in Different Consumer Groups}

Especially, theories engaging in m-ads research context are mainly limited to technology related theories like TAM and TAR. And determinants were too mainly limited to technology related factors. More work is needed in understanding consumer complex behavior related to mobile advertising. One possible perspective would be deploying consumer behavior theories or merging such theories with theories related to technology to produce viable outcomes which could be implemented by marketers. Additionally, examining behavior of different consumers groups (e.g., demographically differentiated groups) would comfort marketers to design better-personalized advertisements.

\section{References}

Adhami, M. (2012). Pushing boundaries: creating outstanding UX for m-commerce succeeds. International Journal of Mobile Marketing, 7(1), 34-39.

Akpojivi, U., \& Bevan-Dye, A. (2015). Mobile advertisements and information privacy perception amongst South African Generation $\mathrm{Y}$ students. Telematics and Informatics, 32, 1-10. https://doi.org/10.1016/j.tele.2014.08.001

Aziz, S., Ghani, U., \& Naizi, A. (2013). Impact of credibility on advertising effectiveness. Pakistan Journal of Commerce and Social Sciences, 7(1), 107-127.

Bakar, M. S. A., \& Bidin, R. (2014). Technology Acceptance and purchase intention towards movie mobile advertising among youth in Malaysia. Procedia-Social and Behavioral Sciences, 130, 558-567. https://doi.org/10.1016/j.sbspro.2014.04.065

Balasubramanian, S., Peterson, R. A., \& Jarvenpaa, S. L. (2002). Exploring the implications of m-commerce for markets and marketing. Acad. Markt Sci. J., 30(4), 348-361. https://doi.org/10.1177/009207002236910

Banerjee, S., \& Dholakia, R. R. (2012). Location-based mobile advertisements and gender targeting. Journal of Research in Interactive Marketing, 6(3), 198-214. https://doi.org/10.1108/17505931211274679

Beneke, J., Cumming, G., Stevens, A., \& Versfeld, M., (2010). Influences on attitude toward mobile text message advertisements: An investigation of South African youth. International Journal of Mobile Marketing, 5(1), 77-97.

Bhave, K., Jain, V., and Roy, S. (2013). Understanding the orientation of Gen Y toward mobile applications and In-App advertising in India. International Journal of Mobile Marketing, 8(1), 62-74.

Brehm, S., \& Brehm, J. W. (1981). Psychological reactance; A theory of freedom and control. New York: Academic Press.

Carroll, A., Barnes, S. J., Scornavacca, E., \& Fletcher, K. (2007). Consumer perceptions and attitudes towards SMS advertising: recent evidence from New Zealand. International Journal of Advertising, 26(1), 79-98.

Chen, L. D., \& Nath, R. (2004). A framework for mobile business application. International Journal of Mobile Communication, 2(4), 368-381. https://doi.org/10.1504/IJMC.2004.005857 
Chen, P. T., \& Hsieh, H. P. (2012). Personalized mobile advertising: Its key attributes, trends and social impact. Technological Forecasting \& Social Change, 79(3), 543-557. https://doi.org/10.1016/j.techfore.2011.08.011

Chen, P. T., Cheng, J. Z., Yu, Y. W., \& Ju, P. H. (2014). Mobile advertising setting analysis and its strategic implications. Technology in Society, 39, 129-141. https://doi.org/10.1016/j.techsoc.2014.09.004

Choi, Y. K., Hwang, J. S., \& McMillan, S. J. (2008). Gearing up for mobile advertising: A cross-cultural examination of key factors that drive mobile messages home to consumers. Journal of Psychology and Marketing, 25(8), 756-768. https://doi.org/10.1002/mar.20237

Chowdhury, H. K., Parvin, N., Weitenberner, C., \& Becker, M. (2006). Consumer attitudes toward mobile advertising in an emerging market: An empirical case study. International Journal of Mobile Marketing, $1(2), 33-41$.

Damnjanovic, V., \& Milicevic J. (2010). The study of the Serbian young consumer attitude toward mobile advertising. Prajana, 13(2), Jul-Dec.

Davis, F. D. (1989). Perceived usefulness, perceived ease of use and user acceptance of information technology. MIS Quarterly, 13, 319-340. https://doi.org/10.2307/249008

DeZoysa, S. (2002). Mobile advertising needs to get personal. Telecommunication International, 36(2), 8.

Dholakia, R. R., \& Dholakia, N. (2004). Mobility and markets: emerging outlines of m-commerce. Journal of Business Research, 57, 1391-1396. https://doi.org/10.1016/S0148-2963(02)00427-7

Drossos, D., Giaglis, G. M., Lekakos, G., Kokkonaki, F., \& Stavaraki, M. G. (2007). Determinant of effective SMS advertising: an empirical study. Journal of Advertising, 7(2).

Figge, S. (2004). Situation-dependent services: a challenge for mobile network operators. Journal of Business Research, 57, 1416-1422. https://doi.org/10.1016/S0148-2963(02)00431-9

Gao, Q. P. L., Rau, P., \& Salvendy, G. (2009). Perception of interactivity: affect s of four key variables in mobile advertising. International Journal of Human-Computer Interaction, 25(6), 479-505. https://doi.org/10.1080/10447310902963936

Gao, Q. P. L., Rau, P., \& Salvendy, G. (2010). Measuring perceived interactivity of mobile advertisement. Behavior \& Information Technology, 29(1), 35-44. https://doi.org/10.1080/01449290802666770

Gavilan, D., Avello, M., \& Abril, C. (2014). The mediating role of mental imagery in mobile advertising. International Journal of Information Management, 34, 457-464. https://doi.org/10.1016/j.ijinfomgt.2014.04.004

Goh, K. Y., Chu, J., \& Wu, J., (2015). Mobile advertising: An empirical study of Temporal and Spatial differences in search behavior and advertising response. Journal of Interactive Marketing, 30, 34-45. https://doi.org/10.1016/j.intmar.2014.12.002

Ha, L. (1996). Observations: Advertising Clutter in Consumer Magazines: Dimensions and Effects. Journal of Advertising Research, 36(4), 76-84.

Hanley, M., Becker, M., \& Martinsen, J. (2006). Factors influencing mobile advertising acceptance: will incentives motive college students to accept mobile advertisements. International Journal of Mobile Marketing, 1(1), 50-58.

Haq, Z. U. (2012). Attitude toward SMS advertising: A survey with reference to Indian Consumers. Journal of Internet Commerce, 11, 271-290. https://doi.org/10.1080/15332861.2012.729463

Hor-Meyll, L. F., Lima, M. C., \& Ferreira, J. B. (2014). Why should I accept Ads on my mobile phone? Factors affecting the acceptance by Brazilian teenagers. Brazilian Business Review, 11(4), 130-150. https://doi.org/10.15728/bbr.2014.11.4.6

http://www.gartner.com/resId=2247015. Last visited date: 14th April 2015.

http://www.hipcricket.com, Last visited date 25th August 2015.

Im, H., \& Ha, Y. (2013). Enablers and inhibitors of permission-based marketing: A case of mobile coupons. Journal of Retailing and Consumer Services, 20, 495-503. https://doi.org/10.1016/j.jretconser.2013.05.002

Izquierdo-Yusta, A., Olarte-Pascual, C., \& Reinares-Lara, E., (2014). Attitude toward mobile marketing among user versus non-users of the mobile internet. Telematics and Informatics, 32, 355-366. https://doi.org/10.1016/j.tele.2014.10.001 
Jun, J. W., \& Lee, S. (2007). Mobile media use and its impact on consumer attitudes toward mobile advertising. International Journal of Mobile Advertising, 2(1), 50-58.

Khan, M. N., \& Allil, K. (2010). Determinants of mobile advertising adoption: A cross-country comparison of India and Syria. International Journal of Mobile Marketing, 5(1), 41-59.

Kim, K. J. (2014). Can smartphone be specialists? Effects of specialization in mobile advertising. Telematics and Informatics, 31, 640-647. https://doi.org/10.1016/j.tele.2013.12.003

Kim, K.Y., \& Lee, B. G. (2014). Marketing insights for mobile advertising and consumer segmentation in the cloud era: A Q-R hybrid methodology and practices. Technological Forecast Change. http://dx.doi.org/10.1016/j.techfore.2014.01.011

Kim, M., Heo, J., \& Chan-Olsted, S. M. (2010). Perceived effectiveness and business structure among advertising agencies: a case study of mobile advertising in South Korea. Journal of Media Business Studies, 7(2), 1-20. https://doi.org/10.1080/16522354.2010.11073504

Kim, Y. J., \& Han, J. Y. (2014). Why smart phone advertising attracts customers: a model of web advertising, flow and personalization. Computers in Human Behavior, 33, 256-269. https://doi.org/10.1016/j.chb.2014.01.015

Kolsaker, A., \& Drakotos, N. (2009). Mobile advertising: The influence of emotional attachment to mobile devices ton consumer receptiveness. Journal of Marketing Communication, 15(4), 267-280. https://doi.org/10.1080/13527260802479664

Koury, S. S., \& Yang, K. C. C. (2010). Factors affecting consumers' responses to mobile advertising from a social norm theoretical perspective. Telematics and Informatics, 27, 103-113. https://doi.org/10.1016/j.tele.2009.06.001

Kucukusta, D., Law, R., Besbes, A., \& Legoherel, P. (2015). Re-examining perceived usefulness and ease of use in online booking: The case of Hong Kong online users. International Journal of Contemporary Hospitality, 27(2), 185-198. https://doi.org/10.1108/IJCHM-09-2013-0413

Lee, K. C., Chung, N., \& Kang, I. (2008). Understanding individual investor's behavior with financial information disclosed on the web sites. Behavior \& Information Technology, 27(3), 219-227. https://doi.org/10.1080/01449290601138146

Leppaniemi, M., \& Karjaluoto, H. (2008). Mobile Marketing: From marketing strategy to mobile marketing campaign implementation. International Journal of Mobile Marketing, 3(1), 50-61.

Li, H., \& Stoller, B. (2007). Parameters of mobile advertising: a field experiment. International Journal of Mobile Marketing, 2(1), 4-11.

Li, H., Edwards, S. M., \& Lee, J-H. (2002). Measuring the Intrusiveness of Advertisements: Scale Development and Validation. Journal of Advertising, 2, 37-47. https://doi.org/10.1080/00913367.2002.10673665

Liu, C. L. E., Sinkpvic, R. R., Pezdrka, N., \& Haghirian, P. (2012). Determinants of consumer perceptions toward mobile advertising: A comparison between Japan and Austria. Journal of Interactive Marketing, 26, 21-32. https://doi.org/10.1016/j.intmar.2011.07.002

Ma, J., Suntornpithug, N., \& Karaatli, G., (2009). Mobile advertising: does it work for everyone? International Journal of Mobile Marketing, 4(2), 28-35.

Maneesoonthorn, C., \& Fortin, D. (2006). Texting behavior and attitudes toward permission mobile advertising: an empirical study of mobile users; acceptance of SMS for marketing purposes. International Journal of Mobile Marketing, 1(1), 66-72.

Merisavo, M., Kajalo, S., Karjaluoto, H., Virtanen, V., Salmankivi, S., Raulas, M., \& Leppaniemi, M. (2009). An empirical study of the drivers of consumer acceptance of mobile advertising. Journal of Interactive Advertising, 7(2), 95-109.

Merisavo, M., Vesanen, J., Arponen, A., Kajalo, S., \& Raulas, M. (2010). The effectiveness of targeted mobile advertising in selling mobile services: An empirical study. International Journal of Mobile Communications, 4(2), 119-127. https://doi.org/10.1504/IJMC.2006.008604

Mobile Marketing Association. $\quad$ (2015). Retrieved from mmaglobal.com/news/mma-updates-definition-mobile-marketing

Moorman, C., Zaltman, G., \& Deshpande, R. (1993). Relationship between providers and users of market 
research: The dynamics of trust within and between organizations. Journal of Marketing Research, 29, 314-328. https://doi.org/10.2307/3172742

Morgan, R. M., \& Hunt, S. D. (1994). The commitment-trust theory of relationship marketing. Journal of Marketing, 58(3), 20-38. https://doi.org/10.2307/1252308

Nakatsu, R. (2010). ECS Entertainment and its future. International Federation for Information Processing (IFIP) AICT 333, 233-242.

Nantel, J., \& Sekhavat. Y. (2008). The impact of SMA advertising on members of a virtual community. Journal of Advertising Research, (September), 363-374. https://doi.org/10.2501/S002184990808032X

Nasco, S. A., \& Bruner II, G. C. (n. d.). Perceptions and recall of advertising content presented on mobile handheld devices. Journal of Interactive Advertising.

Okazaki, S., Katsukura, A., \& Nishiyama, M. (2007). How mobile advertising works: the role of trust in improving attitudes and recall. Journal of Advertising Research, 47, 165-178. https://doi.org/10.2501/S0021849907070195

Park, T., \& Salvendy, G. (2012). Emotional factors in advertising via mobile phones. International Journal of Human-Computer Interaction, 28, 597-612. https://doi.org/10.1080/10447318.2011.641899

Parreno, J. M., Blas, S. S., Mafe, C. R., \& Manzano, J. A. (2013). Key factors of teenagers' mobile advertising acceptance. Industrial Management \& Data Systems, 113(5), $732-749$. https://doi.org/10.1108/02635571311324179

Peng, B. (2006). Mobile marketing: the Chinese perspective. International Journal of Mobile Marketing, 50-59.

Pentina, I., Zhang, L., \& Basmanova, O. (2013). Antecedents and consequences of trust in a social media brand: A cross-cultural study of Twitter. Computers in Human Behavior, 29, 1546-1555. https://doi.org/10.1016/j.chb.2013.01.045

Rohm, A. J., Gao, T., \& Sultan, F. (2012). Brand in the hand: A cross-market investigation of consumer acceptance of mobile marketing. Business Horizons, 585-493. https://doi.org/10.1016/j.bushor.2012.05.004

Salo, J., \& Tahtinen, J. (2005). Retailer use of permission-based mobile advertising. University of Oulu, Finland. https://doi.org/10.4018/978-1-59140-321-0.ch008

Soley, L. C., \& Reid, L. N. (1983). Is the perception of informativeness determined by the quantity or the type of information in advertising? Current Issues and Research in Advertising, 6(1), 241-251.

Strom, R., Vendel, M., \& Bardican, J. (2014), Mobile marketing: A literature review on its value for consumers and retailers. http://dx.doi.org/10.1016/j.jrectconser.2013.12.003

Truong, Y., \& Simmons, G. (2010). Perceived intrusiveness in digital advertising: strategic marketing implications. Journal of Strategic Marketing, 18(3), 239-256. https://doi.org/10.1080/09652540903511308

Tsang, M. M., Ho, S. C., \& Liang, T. P. (2004). Consumer attitudes toward mobile advertising: an empirical study. International Journal of Electronic Commerce, 8(3), 65-78.

Unal, S., Ercis, A., \& Keser, E. (2011). Attitudes towards mobile advertising-A research to determine the differences between the attitudes of youth and adults. Procedia Social and Behavioral Sciences, 24, 361-377. https://doi.org/10.1016/j.sbspro.2011.09.067

Unni, R., \& Harmon, R. (2009). Perceived effectiveness of push vs pull mobile location-based advertising. Journal of Interactive advertising, 7(2).

Varnali, K., Yilmaz, C., \& Toker, A. (2012). Predictors of attitudinal and behavioral outcomes in mobile advertising: a field experiment. Electronic Commerce Research and Applications, 11, 570-581. https://doi.org/10.1016/j.elerap.2012.08.002

Vatanparast, R., \& Butt, A. H. (2010). An empirical study of factors affecting use of mobile advertising. International Journal of Mobile Marketing, 5(1), 28-40.

Watson, C., McCarthy, J., \& Rowley, J., (2013). Consumer attitude towards mobile marketing in the smart phone era. International Journal of Information Management, 33, 840-849. https://doi.org/10.1016/j.ijinfomgt.2013.06.004

Wong, C. H., Tan, G. W. H., Tan, B. I., \& Ooi, K. B. (2015). Mobile Advertising: The changing landscape of the 
advertising industry. Telematics and Informatics, 32, 720-734. https://doi.org/10.1016/j.tele.2015.03.003

Xie, W., \& Zhao, Y. (2013). The effects of interface design of hand-held devices on mobile advertising effectiveness among college students in China. International Journal of Mobile Marketing, 8(1), 46- 61.

$\mathrm{Xu}$, D. J. (2006-2007). The influence of personalization in affecting consumer attitudes toward mobile advertising in China. Journal of Computer Information systems, Winter, 9-19.

Xu, D. J., Liao, S. S., \& Li, Q. (2008). Combining empirical experimentation and modeling techniques: a design research approach for personalized mobile advertising application. Decision Support System, 44, 710-724. https://doi.org/10.1016/j.dss.2007.10.002

Yang, B., Kim, Y., \& Yoo. C. (2013). The integrated mobile advertising model: The effects of technology- and emotion-based evaluations. Journal of Business Research, 66, 1345-1352. https://doi.org/10.1016/j.jbusres.2012.02.035

Yang, H., Zhou, L., \& Liu, H. A. (2010). Comparative study of American and Chinese young consumers' acceptance of mobile advertising: A structural elation modeling approach. International Journal of Mobile Marketing, 5(1), 60-76.

Yang, K. C. C. (2007). Exploring factors affecting consumer intention to use mobile advertising in Taiwan. Journal of International Consumer Marketing, 20(1), 33-49. https://doi.org/10.1300/J046v20n01_04

Yeh, R. K. J., \& Teng, J. T. C. (2012). Extended conceptualization of perceived usefulness: empirical test in the context of information system use continuance. Behavior \& Information Technology, 31(5), 525-540, http://dx.doi.org/10.1080/0144929X.2010.517272

Ying, L., Korneliussen, T., \& Gronhaug, K. (2009). The effect of ad value, ad placement and ad execution on the perceived intrusiveness of web advertisements. International Journal of Advertising, 28, 623-638. https://doi.org/10.2501/S0265048709200795

Yu (Hyunjae), J. (2013). You've got mobile ads! Young consumers' responses to mobile ads with different types of interactivity. International Journal of Mobile Marketing, 5-22.

Zhang, J., \& Mao, E. (2008). Understanding the acceptance of mobile SMS advertising among young Chinese consumers. Psychology and Marketing, 25(8), 787-805. https://doi.org/10.1002/mar.20239

\section{Copyrights}

Copyright for this article is retained by the author, with first publication rights granted to the journal.

This is an open-access article distributed under the terms and conditions of the Creative Commons Attribution license (http://creativecommons.org/licenses/by/4.0/). 